American Journal of Applied Sciences 6 (9): 1731-1741, 2009

ISSN 1546-9239

(C) 2009 Science Publications

\title{
Thermal Comfort Assessment and Optimization of Environmental Factors by Using Taguchi Method
}

\author{
${ }^{1}$ A.R. Ismail, ${ }^{2}$ M.R.A. Rani, ${ }^{3}$ Z.K.M. Makhbul, ${ }^{1}$ K. Sopian and ${ }^{1}$ B.M. Deros \\ ${ }^{1}$ Solar Energy Research Institute, University Kebangsaan Malaysia, 43600 UKM Bangi, Malaysia \\ ${ }^{2}$ Department of Manufacturing Industrial Engineering, Faculty of Mechanical Engineering, \\ University Technology Malaysia, 81310 UTM Skudai, Malaysia \\ ${ }^{3}$ School of Business Management, Faculty of Economics and Business, \\ University Kebangsaan Malaysia, 43600 UKM Bangi, Malaysia
}

\begin{abstract}
Problem statement: The objective of this study was to determine the dominance effects of environmental factors such as Illuminance (lux), relative humidity (\%) and WBGT $\left({ }^{\circ} \mathrm{C}\right)$ on the operators' productivity at Malaysian automotive industry. Approach: One automotive parts assembly factory had been chosen as a subject for the study. The subjects were workers at the assembly section of the factory. The environment examined was the Illuminance (lux), relative humidity $(\%)$ and $\mathrm{WBGT}\left({ }^{\circ} \mathrm{C}\right)$ of the surrounding workstation area. Two sets of representative data including the Illuminance, relative humidity $(\%)$ and WBGT $\left({ }^{\circ} \mathrm{C}\right)$ level and production rate were collected during the study. All the data was measured using Babuc apparatus which is capable to measure simultaneously those mentioned environmental factors. The time series data of fluctuating level of environmental were plotted to identify the significant changes of factors. Then Taguchi Method was being utilized to find the sequence of dominance factors that contributed to the productivity of operator at the specified production workstation. From there, optimum level for the three factors will be determine for optimum productivity. Further multiple linear regressions were employed to obtain the equation model in order to represent the relationship of these environmental factors towards productivity. Results: the thermal comfort assessments of this station which was the scale PMV was 2 and PPD is 79\% ware likely to be satisfied by the worker. Conclusion: The study revealed that the dominant factor contribute to the productivity at the body assembly production line is WBGT and Illuminance whereas the empirical finding was closely related to the perception study by survey questionnaire distribution.
\end{abstract}

Key words: Productivity, illuminance, humidity, WBGT, optimum

\section{INTRODUCTION}

Robust design is an engineering methodology for obtaining product and process conditions, which are minimally sensitive to the various causes of variation to produce high-quality products with low development and manufacturing costs ${ }^{[31]}$. Taguchi's parameter design is an important tool for robust design. It offers a simple and systematic approach to optimize design for performance, quality and cost. Two major tools used in robust design are ${ }^{[22,27,31]}$ :

- Signal to noise ratio, which measures quality with emphasis on variation

- Orthogonal arrays, which accommodate many design factors simultaneously
Taguchi's approach is totally based on statistical design of experiments ${ }^{[31]}$. By applying this technique one can significantly reduce the time required for experimental investigation, as it is effective in investigating the effects of multiple factors on performance as well as to study the influence of individual factors to determine which factor has more influence, which less ${ }^{[31]}$.

Some of the previous researches that used the Taguchi method as tool for design of experiment in various areas including metal cutting are listed in the references ${ }^{[3,4,14,17,25,34,36]}$.

The most important stage in the design of an experiment lies in the selection of control factors. As many factors as possible should be included, so that it would be possible to identify non-significant variables

Corresponding Author: A.R. Ismail, Solar Energy Research Institute, University Kebangsaan Malaysia, 43600 UKM Bangi, Malaysia 
at the earliest opportunity. Taguchi creates a standard orthogonal array to accommodate this requirement. Depending on the number of factors, interactions and levels needed, the choice is left to the user to select either the standard or column-merging method or idlecolumn method, or so on. Two of the applications in which the concept of $\mathrm{S} / \mathrm{N}$ ratio is useful are the improvement of quality through variability reduction and the improvement of measurement. The $\mathrm{S} / \mathrm{N}$ ratio characteristics can be divided into three categories when the characteristic is continuous ${ }^{[31]}$ :

Nominal is the best characteristic:

$\mathrm{S} / \mathrm{N}=10 \log \frac{\overline{\mathrm{y}}}{\mathrm{s}_{\mathrm{y}}^{2}}$

Smaller the better characteristics:

$\mathrm{S} / \mathrm{N}=-10 \log \frac{1}{\mathrm{n}}\left(\sum \mathrm{y}^{2}\right)$

Larger the better characteristics:

$\mathrm{S} / \mathrm{N}=-10 \log \frac{1}{\mathrm{n}}\left(\sum \frac{1}{\mathrm{y}^{2}}\right)$

Where:

$\bar{y}=$ The average of observed data

$\mathrm{s}_{\mathrm{y}}^{2}=$ Variance of $\mathrm{y}$

$\mathrm{n}=$ Number of observations

$\mathrm{y}=$ The observed data

For each type of the characteristics, with the above $\mathrm{S} / \mathrm{N}$ ratio transformation, the higher the $\mathrm{S} / \mathrm{N}$ ratio the better is the result.

Improving workers' productivity, occupational health and safety are major concerns of industry, especially in developing countries. However, these industries are featured with improper workplace design, ill-structured jobs, mismatch between workers' abilities and job demands, adverse environment, poor humanmachine system design and inappropriate management programs ${ }^{[29]}$. Light, noise, air quality and the thermal environment were considered factors that would influence the acceptability and performance on the occupants of premises ${ }^{[5,24]}$ stated that lower emotional health is manifested as psychological distress, depression and anxiety, whereas lower physical health is manifested as heart disease, insomnia, headaches and infections ${ }^{[5]}$. These health problems could lead to organizational symptoms such as job dissatisfaction, absenteeism and poor work quality. Irritated, sore eyes and throat, hoarseness, stuffy congested nose, excessive mental fatigue, headache and unusual tiredness were all signs of the negative workplace environmental conditions $^{[32]}$.

Previous research done by ${ }^{[6]}$ showed that the work environments were associated with perceived effects of work on health. This research used a national sample of 2,048 workers who were asked to rate the impact of their respective jobs job on their physical and mental health. Regression analyses proved that the workers' responses were significantly correlated with health outcomes. In addition to this, Shikdar et al. ${ }^{[29]}$ pointed out that there was high correlation between performance indicators and health, facilities and environmental attributes. In other words, companies with higher health, facilities and environmental problems could face more performance related problems such as low productivity and high absenteeism. Employees with complaints of discomfort and dissatisfaction at work could have their productivity affected, result of their inability to perform their work properly ${ }^{[19]}$.

According to the Fisk et. al productivity was one of the most important factors affecting the overall performance to any organization, from small enterprises to entire nations ${ }^{[9]}$. Increased attention had focused on the relationship between the work environment and productivity since the 1990s. Laboratory and field studies showed that the physical and chemical factors in the work environment could have a notable impact on the health and performance of the occupants and consequently on the productivity. Workplace environmental conditions, such as humidity, indoor air quality and acoustics have significant relationships with workers' satisfaction and performance ${ }^{[23,32]}$. Indoors air quality could have a direct impact on health problems and leads to uncomfortable workplace environments ${ }^{[2,28,35]}$.

The ventilation of building is used to maintain indoor air quality and thermal comfort. In order to attain these objectives, airflow rate should be controlled. The minimal airflow rate is determined by indoor air quality requirements so that the maximal concentration for every pollutant is lower than the maximum admitted. Thermal comfort is influenced by air parameters (temperature, humidity, velocity and turbulence) and surface temperatures (walls, windows) but also by the type of human activity and clothing.

Thermal comfort has a great influence on the productivity and satisfaction of indoor building occupants $^{[33]}$. Thermal comfort is very difficult to define. This is because we need to take into account a 
range of environmental and personal factors when deciding on the temperatures and ventilation that will make feel comfortable. The best that we can realistically hope to achieve is a thermal environment which satisfies the majority of people in the workplace, or put more simply, 'reasonable comfort' ${ }^{\text {[18] }}$.

Thermal comfort can be defined as that condition of mind which expresses satisfaction with the thermal environment $^{[30]}$. The reference to 'mind' indicates that it is essentially a subjective term; however, there has been extensive research in this area and a number of indices exist which can be used to assess environments for thermal comfort ${ }^{[7,15]}$. Atmaca ${ }^{[11]}$ suggested three conditions for comfort; these are that the body is in heat balance and that the mean skin temperature and sweat rate are within limits required for comfort. Conditions required for heat balance can be derived from a heat balance equation. Mean skin temperatures and sweat rates that are acceptable for comfort have been derived from empirical investigation ${ }^{[21]}$.

Predicted Mean Vote (PMV) is a parameter for assessing thermal comfort in an occupied zone based on the conditions of metabolic rate, clothing, air speed besides temperature and humidity. PMV values refer the ASHRAE thermal sensation scale ${ }^{[21]}$ that ranges from -3 to 3 as follows: $3=$ hot, 2 = warm, $1=$ slightly warm, $0=$ neutral, -1 = slightly cool, $-2=$ cool, $-3=$ cold. Figure 1 summarizes the overall process of using the six variables associated with thermal comfort sensation to evaluate the $\mathrm{PMV}^{[1]}$. The general comfort equation developed by Fanger ${ }^{[21]}$ to describe the conditions under which a large group of people will feel in thermal neutrality is too complex and cannot be used in real time applications:

$$
\begin{aligned}
\text { PMV }= & \left(0.028+0.3033 \mathrm{e}^{-0.036 \mathrm{M}}\right)\{(\mathrm{M}-\mathrm{W})-3.05 \\
& {[5.733-0.000699(\mathrm{M}-\mathrm{W})-\mathrm{Pa}] } \\
& -0.42[(\mathrm{M}-\mathrm{W})-58.15]-0.0173 \\
& \mathrm{M}(5.867-\mathrm{Pa})-0.0014 \mathrm{M}\left(34-\mathrm{T}_{\mathrm{a}}\right) \\
& -3.96 \times 10^{-8} \mathrm{fcl}\left[\left(\mathrm{T}_{\mathrm{cl}}+273\right)^{4}-\left(\mathrm{T}_{\mathrm{mrt}}+273\right)^{4}\right] \\
& \left.- \text { fcl.hc }\left(\mathrm{T}_{\mathrm{cl}}-\mathrm{T}_{\mathrm{a}}\right)\right\}
\end{aligned}
$$

Where:

$$
\begin{aligned}
\mathrm{T}_{\mathrm{cl}}= & 35.7-0.028(\mathrm{M}-\mathrm{W}) \\
& -0.155 \mathrm{I}_{\mathrm{cl}}\left[3.96 \times 10^{-3} \mathrm{fcl}\left[\left(\mathrm{T}_{\mathrm{cl}}+273\right)^{4}\right.\right. \\
& \left.-\left(\mathrm{T}_{\mathrm{mrt}}+273\right)^{4}\right]-\operatorname{fcl} . \mathrm{hc}\left(\mathrm{T}_{\mathrm{cl}}-\mathrm{T}_{\mathrm{a}}\right)
\end{aligned}
$$

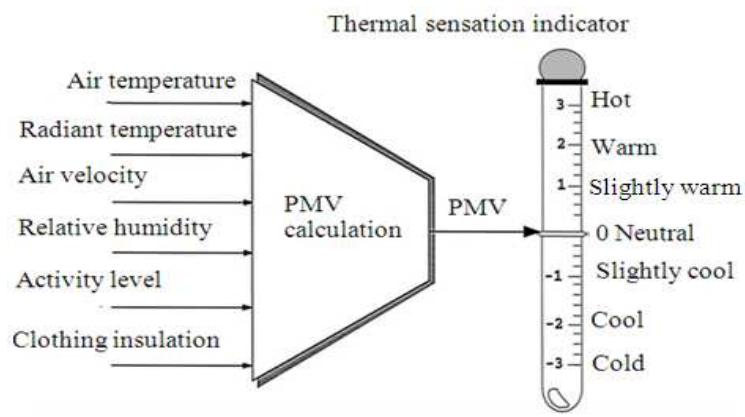

Fig. 1: PMV and thermal sensation

$h_{c}=\left\{\begin{array}{l}2.38\left(\mathrm{~T}_{\mathrm{cl}}-\mathrm{T}_{\mathrm{a}}\right)^{0.25} \text { for } 2.38\left(\mathrm{~T}_{\mathrm{cl}}+\mathrm{T}_{\mathrm{a}}\right)^{0.25} \geq 12.1 \sqrt{\mathrm{V}_{\text {air }}} \\ 12.1 \sqrt{\mathrm{V}_{\text {air }}} \text { for } 2.38\left(\mathrm{~T}_{\mathrm{cl}}-\mathrm{T}_{\mathrm{a}}\right)^{0.25} \leq 12.1 \sqrt{\mathrm{V}_{\text {air }}}\end{array}\right.$

The parameters are defined as follows:

$\mathrm{PMV}=$ Predicted mean vote

$\mathrm{M}=$ Metabolism $\left(\mathrm{W} \mathrm{m}^{-2}\right)$

$\mathrm{W}=$ External work, equal to zero for most activity $\left(\mathrm{W} \mathrm{m}^{-2}\right)$

$\mathrm{I}_{\mathrm{cl}} \quad=$ Thermal resistance of clothing (Clo)

$\mathrm{f}_{\mathrm{cl}}=$ Ratio of body's surface area when fully clothed to body's surface area when nude

$\mathrm{T}_{\mathrm{a}}=$ Air temperature $\left({ }^{\circ} \mathrm{C}\right)$

$\mathrm{T}_{\text {mrt }}=$ Mean radiant temperature $\left({ }^{\circ} \mathrm{C}\right)$

$\mathrm{V}_{\text {air }}=$ Relative air velocity $\left(\mathrm{m} \mathrm{sec}^{-1}\right)$

$\mathrm{Pa}=$ Partial water vapor pressure $(\mathrm{Pa})$

$\mathrm{h}_{\mathrm{c}} \quad=$ Convectional heat transfer coefficient $\left(\mathrm{W} \mathrm{m} \mathrm{m}^{-2} \mathrm{~K}\right)$

$\mathrm{T}_{\mathrm{cl}}=$ Surface temperature of clothing $\left({ }^{\circ} \mathrm{C}\right)$ Eq. 4:

Furthermore, the equation for PPD is given by

$\mathrm{PPD}=100-95 \exp \left(-0.03353 \mathrm{PMV}^{4}+0.2179 \mathrm{PMV}^{2}\right)$

Predicted Percentage Dissatisfied (PPD) is used to estimate the thermal comfort satisfaction of the occupant. It is considered that satisfying 80 of occupant is good: That is, PPD less than $20 \%$ is good $^{[37]}$.

Without ventilation, a building's occupants will first be troubled by adores and other possible contaminants and heat ${ }^{[11]}$. When we discuss about heat, actually automatically discuss about thermal comfort building's occupant. In most cases, buildings are erected to protect their occupants from the external environment (e.g., extreme temperatures, wind, rain and radiation) and to provide them with a good indoor environment. Proton Plant is using natural ventilation. 
This ventilation is different with mechanical ventilation. Three objectives of natural ventilation are indoor air quality, thermal comfort and energy savings $^{[11]}$.

The good building design characteristic, including both the engineering and non engineering disciplines, might be summarized as follow:

- Meets the purpose and needs of the building's owners/managers and occupants

- Meets the requirements of health, safety and environmental impact as prescribed by codes and recommend by consensus standards

- Achieves good indoor environment quality which in turn encompasses high quality in the following dimensions: Thermal comfort, indoor air quality, acoustical comfort, visual comfort

- Creates the intended emotional impact on the building's occupants and beholders

The building envelopes are the main factors of building energy efficiency and human thermal comfort, as they represent a skin of the buildings body ${ }^{[11]}$. The building whose envelops include suitable insulation has little internal heat gains and outside gains from solar radiation and in such a situation, the interior surface temperature of the building walls helps in defending from outside environmental conditions. In buildings where envelopes are un-insulated, the interior surface temperature of the building walls is affected from the outside environmental conditions, especially the solar radiation.

The relationship between thermal comfort and acceptability was investigated by ${ }^{[10]}$. He compared the effect of temperatures that deviate from those of optimum comfort assessed by percent comfortable ${ }^{[10]}$ with the one by thermal acceptability and found that they were quite similar, which indicates that the thermal comfort votes falling in comfortable or slightly uncomfortable range were perceived by the subjects as acceptable. The comparison was conducted under uniform environment and the for non-uniform environment remains vacant ${ }^{[38]}$.

Achieving thermal comfort is usually paramount in buildings involving people occupancy. In most buildings this requires the addition or extraction of heat from the space by the HVAC system depending mainly on the season and type of activities performed indoors $^{[13]}$. The use of HVAC systems for achieving the desired comfort conditions through complicated heat and moisture removal process has raised the possibility of thermal comfort problems in building. Thermal comfort problems have an immediate and direct impact on building occupant morale and productivity: Therefore immediate attention should be given to thermal comfort related complaints. Furthermore, minimum time and effort should be utilized for rectifying problems ${ }^{[13]}$.

Improving workers' productivity, occupational health and safety are major concerns of industry, especially in developing countries. However, these industries are featured with improper workplace design, ill-structured jobs, mismatch between workers' abilities and job demands, adverse environment, poor humanmachine system design and inappropriate management programs $^{[26]}$. Light, noise, air quality and the thermal environment were considered factors that would influence the acceptability and performance on the occupants of premises ${ }^{[12]} \cdot{ }^{[7]}$ stated that lower emotional health is manifested as psychological distress, depression and anxiety, whereas lower physical health is manifested as heart disease, insomnia, headaches and infections. These health problems could lead to organizational symptoms such as job dissatisfaction, absenteeism and poor work quality. Irritated, sore eyes and throat, hoarseness, stuffy congested nose, excessive mental fatigue, headache and unusual tiredness were all signs of the negative workplace environmental conditions $^{[7]}$.

Previous research done by ${ }^{[16]}$ showed that the work environments were associated with perceived effects of work on health. This research used a national sample of 2048 workers who were asked to rate the impact of their respective jobs job on their physical and mental health. Regression analyses proved that the workers' responses were significantly correlated with health outcomes. In addition to this, Shikdar et al. ${ }^{[29]}$ pointed out that there was high correlation between performance indicators and health, facilities and environmental attributes ${ }^{[26]}$. In other words, companies with higher health, facilities and environmental problems could face more performance related problems such as low productivity and high absenteeism. Employees with complaints of discomfort and dissatisfaction at work could have their productivity affected, result of their inability to perform their work properly $^{[20]}$.

Increased attention had focused on the relationship between the work environment and productivity since the 1990s. Laboratory and field studies showed that the physical and chemical factors in the work environment could have a notable impact on the health and performance of the occupants and consequently on the productivity. Workplace environmental conditions, such as humidity, indoor air quality and acoustics have significant relationships with workers' satisfaction and performance $^{[2,8,16]}$. Indoors air quality could have a 
direct impact on health problems and leads to uncomfortable workplace environments ${ }^{[15,28,35]}$.

\section{MATERIALS AND METHODS}

Description of Drum Tester workstation: The workplace to be measured was the one down in the pit. This area is more or less divided from the area above and was supposed to have some characteristic conditions. In the pit, the worker is standing on a small platform to have the possibility to reach each part of the suspension easily. To adjust the suspension he has to turn two screws on each side and fasten them with a torque wrench. The measurement devices were placed close to the platform in one corner of the pit, illustrated in Fig. 2 and 3. They could not been place on the platform. Otherwise the worker would have been disturbed in his job. The illumination in the pit was uniform and no tool, emitting loud sounds was used. The temperature and humidity can be regarded as constant in the pit. The small distance to the worker will not manipulate the measured data. Four large Fans are used to cool down the temperature in the pit and several strip lights illuminate the place to give the worker a good view to the front suspension. No special task light was used. The measured data were recorded during the whole day.

Also the cars being checked and adjusted were counted. It was not useful to measure the cycle time at this station. On the one hand the time was predicted by the computer system. On the other hand, the workers had to wait allot of times for the next station to be cleared. The times to measure the alignment were default by the system. Once they were displayed, the worker in the pit could start his job. The time to adjust the suspension was basing on the amount, it had to be changed and differed from car to car. The workers were rotating their position. While one was driving the car at a measurement, he adjusted the headlights the next time and the following time he had to work in the pit. Each worker had his own speed. Representative measurements of a time to indicate a change in productivity were not possible. The questionnaires were spread out as usually after 5:20 pm. This station with the characteristic pit underneath the testing line had no equal station close to it. Only the workers belonging to this station and been ask to participate the survey.

Equipments: These buildings usually have a central fan or local fans that provide the ventilation air. The basic device for the measurements was the Babuc A multi-data inquisition unit as a shown in Fig. 4.

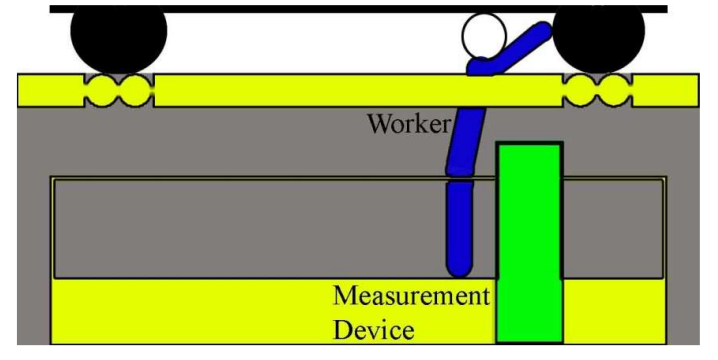

Fig. 2: Position of the measurement device

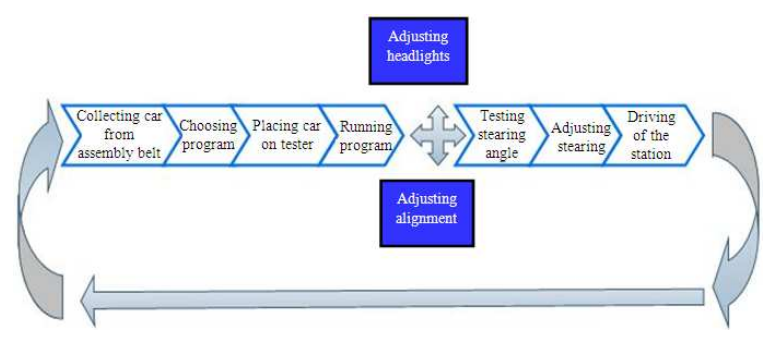

Fig. 3: Workflow at the drum tester station

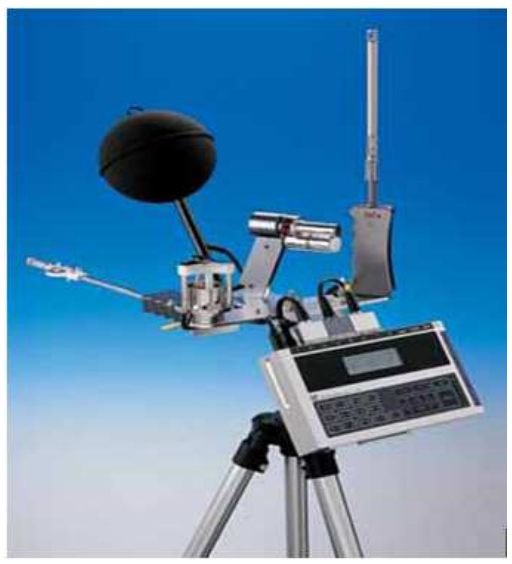

Fig. 4: Complete integrated Babuc A apparatus

This instrument was used to obtain value air temperature, air humidity, mean radiant temperature, relative air velocity, activity level (heat production in the body), thermal resistance of the clothing (clo-value).

Descriptions of subjects: At this station only four workers took part. The average age at this station is 32 , ranging between 21 and 41 . The 21 year old worker is a single, working in the job for 2 years or less. The others are married with children being in their job for 10 years and above. Two have an educational level SPM; one went to a vocational school and one finished with Industrial Training (LI). The three older workers are employed permanent, the younger one just on contract. 


\section{RESULTS}

Time series: The temperature in the pit was increasing during the day. But different to other stations the temperature range was a little lower. The first temperatures measured, starting 8:50 am, were rising from $25.5^{\circ} \mathrm{C}$ to almost $27^{\circ} \mathrm{C}$, at $11: 50 \mathrm{am}$. A small drop can be noticed during the time of the first break. It can be seen clearly in Fig. 5. Between 12:30 and 1:30 pm again a drop occurred. A reason might have been the missing of cars, passing this station, but the temperatures rise again from 1:30 pm on. During this time no cars were on this station yet. Additionally the cars were started the first time before they enter this station. The engine would only heat up a little during the short period running. The exhaust gases were also not sufficient to heat up the pit. The light had not been shut down neither. Until 4:20 pm the temperature rose up to values above $27.5^{\circ} \mathrm{C}$ to decrease from this time on just slightly. This station also was operated by workers, wearing shirts with short sleeves but the work was only rated as light work. The according values are 1.72 met and $1.1 \mathrm{clo}$. Hence the metabolic rate is $100 \mathrm{~W} / \mathrm{m}^{2}$. The resulting reference temperature is again $30^{\circ} \mathrm{C}$. The measured maximum temperature is close to $28^{\circ} \mathrm{C}$, almost in the acceptable range.

The humidity curve is the inverse of the temperature curve. Starting with values of around 70\% relative humidity, the tendency is decreasing. During the time of the lunch break a little bump is visible in the graph. This can be seen in Fig. 6 too. Before this, the humidity decreased to values around 55\%. The short rise of humidity goes up to $60 \%$. The difference is not much, but noticeable. Until 3:30 pm the humidity decreased again to 55\% and climbed up afterwards to values of $60 \%$. The overall changes were just of minor significance, but the reciprocal behavior to the temperature curve is eye catching. The values ranged most of the time around $60 \%$ which is almost in the recommended range.

The illuminance shows some special behaviors too. The overall behavior is decreasing. This is a surprise, because the illumination in the pit was more or less only depending on the strip lights in the pit. They should have provided a constant illumination. Whenever a car was placed above the pit, the illuminance decreased significant. Caused by this fact the break times are clearly to identify.

During the breaks, the overall illuminance increased. This effect is well noticeable in Fig. 7. Between the start of the measurements and the first break, the illuminance was ranging, almost constant,

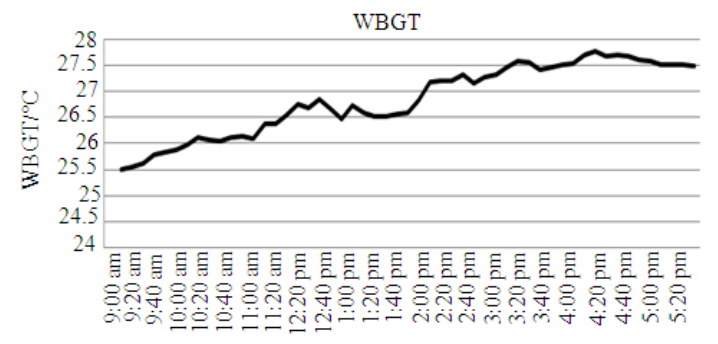

Fig. 5: WBGT measured at the drum tester station

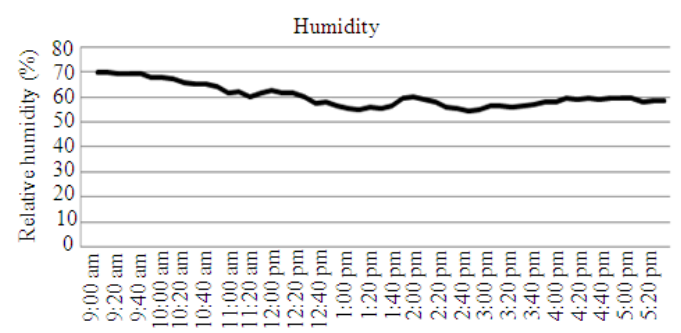

Fig. 6: Relative humidity measured at the drum tester station

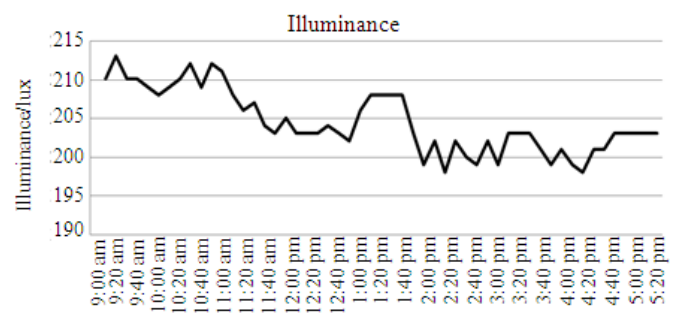

Fig. 7: Illuminance measured at the drum tester

around values of 210 lux. After the lunch break the illuminance is almost constant too, but the values dropped to 200 lux in average. The ups and downs are caused by cars on the station, or not. The decrease between the first break and the lunch break is confusing. No change in the illumination was noticeable. The position of the measurement devices was not changed neither. The task can be rated as high contrast, because in the pit, task lights were used. The measured values represent more or less the conditions with task light and are in the range of 200-500 lux.

\section{DISCUSSION}

The productivity was hard to analyze. Because no time could be measured, just the amount of cars leaving the tester was counted. The number ranged between two and four cars, most of the time three. The reason is simply the speed of the assembly belt. 
Am. J. Applied Sci., 6 (9): 1731-1741, 2009

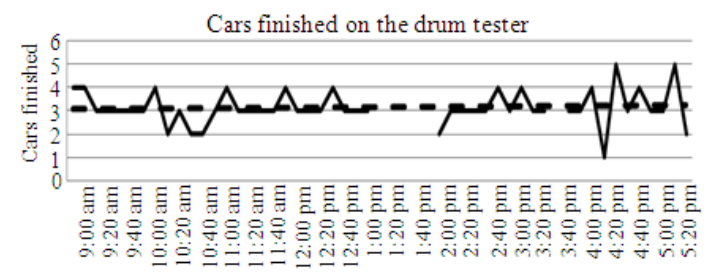

Fig. 8: Productivity measured at the drum tester station

Just every three min one car leaves the belt. In $10 \mathrm{~min}$ 3.3 cars could be possible tested, which ends in the result of three, sometimes four. The behavior can be shown in Fig. 8.

Whenever the next station was not cleared, the workers at the drum tester had to wait. Sometimes just two cars could leave the tester in ten min. This was made up by testing four cars in $10 \mathrm{~min}$. The station after the drum tester was the engine test. Allot of cars had to repeat the engine test again. They were driven to the tester through a gate at the side of the plant and blocked the testing of the just finished cars from the assembly belt. The cars, driven to the drum tester were powered the first time. Through the day seven cars did not started and had to be reworked. But sooner or later they came back to the drum tester. The amount of three cars in average could be kept through the day. The study at this station was overall only light work. The driver just had to sit in the car and operate some tools. The worker to adjust the head light had to move a device, guided on a rail and to adjust two screws and the worker in the pit, doing the decisive job for this measurement. He just had to adjust and fasten 4 screws. This can be also considered as light work. The pit was equipped with large fans to keep the temperature low, but just in case of a heat accumulation in the pit. The study itself was not exhausting at all. Even if, was the time for the next car to be adjusted long enough to rest. The correlation between the environmental factors and the productivity is like expected very low. Beside the difficulties to rate the productivity at this station, the environmental factors had many other influences.

Thermal comfort assessment: The day at the drum tester was calm with only scattered clouds. But the station at some different conditions, compared to the previous ones. The measurement devices were diploid in a pit, below the floor level. The according values are 1.72 met and 1.1 clo. Hence the metabolic rate is $100 \mathrm{~W} \mathrm{~m}^{-2}$. The PMV index is 2 . But the PPD is around $74.2-78.5 \%$. So, $21.5 \%$ from worker satisfied with this environment (Fig. 9).

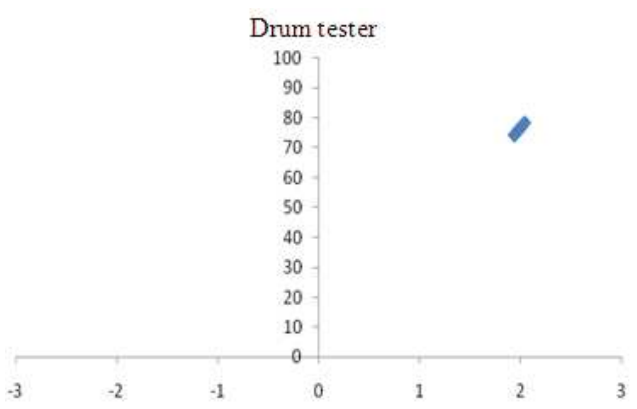

Fig. 9: Predicted Percentage of Dissatisfied (PPD) as a function of Predicted Mean Vote (PMV) in the drum tester station

Table 1: Correlation coefficients for the drum tester station

\begin{tabular}{lll}
\hline WBGT & Humidity & Illuminance \\
\hline 0,05697599 & $-0,00651093$ & $-0,0544993$ \\
\hline
\end{tabular}

\begin{tabular}{llllll}
\multicolumn{5}{c}{ Table 2: L9 Array for the Taguchi method for the drum tester station } \\
\hline $\begin{array}{lllll}\text { Observation } \\
\text { WBGT }\end{array}$ & $\begin{array}{l}\text { Humidity } \\
(\%)\end{array}$ & $\begin{array}{l}\text { Illuminance } \\
\text { (lux) }\end{array}$ & $\begin{array}{l}\text { Productivity } \\
\text { parts }\end{array}$ & $\begin{array}{l}\text { S/N } \\
\text { ratio }\end{array}$ \\
\hline 1 & 26 & 63 & 206 & 4 & 12,04 \\
2 & 26 & 65 & 209 & 3 & 9,54 \\
3 & 26 & 70 & 213 & 4 & 12,04 \\
4 & 27 & 55 & 206 & 3 & 9,54 \\
5 & 27 & 56 & 208 & 3 & 9,54 \\
6 & 27 & 63 & 203 & 3 & 9,54 \\
7 & 28 & 56 & 203 & 4 & 12,04 \\
8 & 28 & 58 & 199 & 3 & 9,54 \\
9 & 28 & 60 & 201 & 3 & 9,54 \\
\hline
\end{tabular}

Statistical data analysis: The strongest correlation is between the WBGT and the productivity. This is caused by the fact, that both are more or less constant at one level. The other values are definitely not significant at all. The numbers can be seen in Table 1 .

The data measured at this day were again very hard to be inserted into the array for the Taguchi calculation. The temperature is increasing while the illuminance is decreasing. The humidity is almost constant. Only the three other factors are included. The productivity could also only be stated in numbers of cars finished in $10 \mathrm{~min}$. The results differ only between 3 and 4 cars finished. This is not the best method to present the productivity, but the only useful. All results are presented in Table 2.

The resulting mean values for the $\mathrm{S} / \mathrm{N}$ ration are surprisingly matching the expectations. The temperature and humidity are at level one at the optimal level. The illuminance is optimal for level three, which is making sense. Level three is the highest illuminance level. But the illuminance was decreasing at this station, while the number of finished cars increased to the end of the day. This result is a contradiction with the measured data. The values are shown in Table 3. 
Am. J. Applied Sci., 6 (9): 1731-1741, 2009

Table 3: Optimum levels for the drum tester station

\begin{tabular}{lllll}
\hline & Level 1 & Level 2 & Level 3 & Optimal \\
\hline WBGT & 11,21 & 9,54 & 10,38 & Level 1 \\
Humidity & 11,21 & 9,54 & 10,38 & Level 1 \\
Illumiance & 10,38 & 9,54 & 11,21 & Level 3 \\
\hline
\end{tabular}

Table 4: Analysis of variance for the drum tester station

\begin{tabular}{llllll}
\hline Factor & $\begin{array}{l}\text { Degree } \\
\text { of } \\
\text { freedom }\end{array}$ & $\begin{array}{l}\text { Sum of } \\
\text { Squares } \\
\text { (SS) }\end{array}$ & $\begin{array}{l}\text { Mean } \\
\text { Square } \\
\text { (MS) }\end{array}$ & F-value & $\begin{array}{l}\text { Contribution } \\
(\%)\end{array}$ \\
\hline WBGT & 2 & 4 & 2 & 0 & 33,3 \\
Humidity & 2 & 4 & 2 & 0 & 33,3 \\
Illumiance & 2 & 4 & 2 & 0 & 33,3 \\
Error & 2 & 0 & 0 & & 0 \\
Total & 8 & 12 & 6 & & 100 \\
\hline
\end{tabular}

The results of the analysis of variance are again not very representative. All F-values are far below zero. The contribution is equal between all factors. The correlation between the environmental factors and the performance at this station was not high enough, to result in meaningful results. All results are listed in Table 4.

The predicted $\mathrm{S} / \mathrm{N}$ ration is 10.38 with a possible error of 2.63. The predicted number of cars is 3.3 in a range between 2.44 and 4.47. The prediction matches the actual possible amount perfect.

For the single regression the following equations could be set up:

$$
\text { Productivity }=-0,06 \mathrm{X}_{\mathrm{WBGT}}+1,53
$$

The standard error for the slope is 0.16 , which is very large and for the intercept 4.23 , also very large. The random error is 0.57 , the F-value 0.146 and the variability, represented by $R^{2}$ is 0.003 :

$$
\text { Productivity }=-0,0021 \mathrm{X}_{\text {Humidity }}+3,22
$$

For the equation belonging to the humidity data the standard error for the slope is 0.024 and for the intercept 1.48. The value for the slope error is quite high. The significance is according to the F-value 0.0023 , which is very low and the variability is according to the $\mathrm{R}^{2}$ value 0.00005 . The random error is 0.57 :

$$
\text { Productivity }=-0,0095 \mathrm{X}_{\text {Illuminance }}+5,086
$$

The equation for the multi regression resulted of the also very low regression coefficients, indicating small slopes, evaluated by the multi regression analysis:

$$
\begin{aligned}
\text { Productivity }= & 1,98+0,089 \mathrm{X}_{\mathrm{WBGT}}+0,017 \mathrm{X}_{\mathrm{Humidity}} \\
& -0,011 \mathrm{X}_{\text {Illuminance }}
\end{aligned}
$$

Table 5: Comparison of the prediction for the drum tester station

\begin{tabular}{llllll}
\hline Observation & $\begin{array}{l}\text { WBGT } \\
\left({ }^{\circ} \mathrm{C}\right)\end{array}$ & $\begin{array}{l}\text { Humidity } \\
(\%)\end{array}$ & $\begin{array}{l}\text { Illuminance } \\
\text { (lux) }\end{array}$ & $\begin{array}{l}\text { Productivity } \\
\text { parts }\end{array}$ & $\begin{array}{l}\text { S/N } \\
\text { ratio }\end{array}$ \\
\hline 1 & 26 & 63 & 206 & 4 & 3 \\
2 & 26 & 65 & 209 & 3 & 3 \\
3 & 26 & 70 & 213 & 4 & 3 \\
4 & 27 & 55 & 206 & 3 & 3 \\
5 & 27 & 56 & 208 & 3 & 3 \\
6 & 27 & 63 & 203 & 3 & 3 \\
7 & 28 & 56 & 203 & 4 & 3 \\
8 & 28 & 58 & 199 & 3 & 3 \\
9 & 28 & 60 & 201 & 3 & 3 \\
\hline
\end{tabular}

The standard errors of the slopes are for WBGT 0.35 , for the humidity value 0.042 and for the illuminance 0.063 . All values are larger than the slopes. The error of the interception is 20.37 , a very large value. The random error is 0.6 , the significance is rated with 0.1 and the variability according to the $\mathrm{R}^{2}$ value is 0.007 .

The comparison between the predicted values, using the equation and the actual values, used for the Taguchi method again shows values, sometimes matching, but also many times not. The results just represented in the number of cars leaving the Drum Tester Station is for sure not the optimal way, but no other possibility could be found, to match the 10 min range.

At least the predicted values are matching the right range of possible results. All values are presented in Table 5.

Servey result: At the drum tester station only four people participated at the survey. Unfortunately the workers went of the station during every break and after the end of the shift, the workers left the station very fast. Six workers were operating this station and at least four could be asked to fill out the questionnaires.

The temperature seems to be very disturbing at the drum tester station. The answers to the questions about the temperature are all much, or very much. The measured temperature at this station was, compared to other stations not the highest, but it seemed to affect the workers allot. The maximum temperature was around $27.5^{\circ} \mathrm{C}$. At other stations, temperatures around $29^{\circ} \mathrm{C}$ could be measured. The average was around $27^{\circ} \mathrm{C}$. The range was quite close all over the day. The study was not really exhausting, so the results in somehow surprising. Compared to all other six stations, this station was the most comfortable, due to the personal impression. All results of the survey are presented in Fig. 10.

The humidity was not as affecting, than the temperature. The answers about the humidity show, that the humidity was not a burden for the workers. Meanwhile two answered, they feel affected and disturbed allot, two others did not feel disturbed at all. 


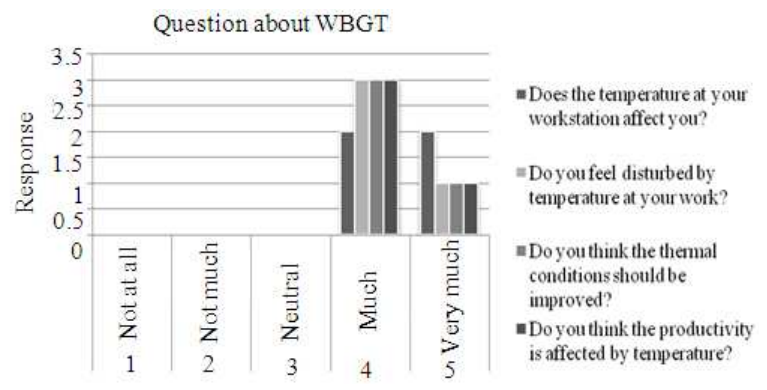

Fig. 10: Affection of the WBGT at the drum tester station

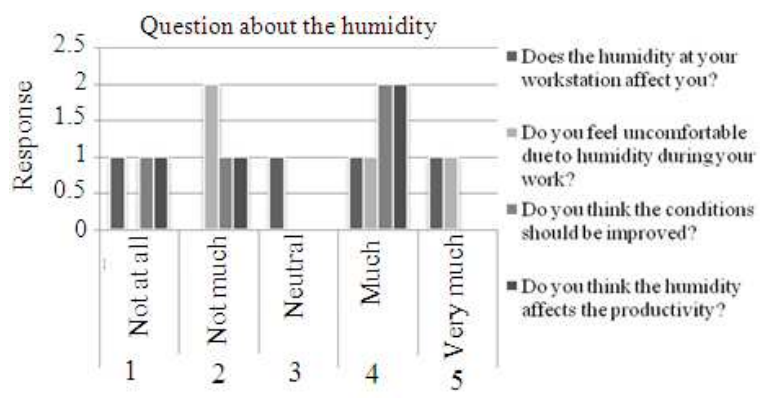

Fig. 11: Affection of the relative humidity at the drum tester station

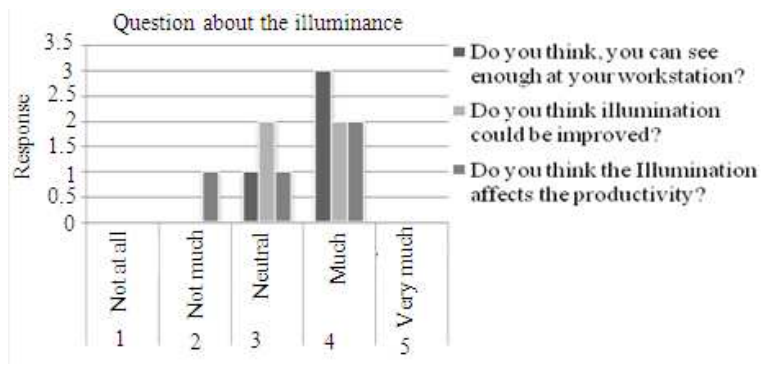

Fig. 12: Affection of the illuminance at the drum tester station

The tasks to be fulfilled were not that exhausting, that the operators could have had problems with sweating. At all, the answers are spread through the whole range of possible answers, which is shown in Fig. 11.

The illuminance is no real problem at this station. Most of the operators comment, that the illumination is sufficient. Improvement is suggested by two, but two others did not care about. The conditions did not seem to disturb the workers allot. The measured data are increasing to some reason, but at all the values were very high, between 200 and 210 lux. Again the measured data match with the impression of the workers. The results are presented in the Chart in Fig. 12.

\section{CONCLUSION}

Research on the relationship of workplace environmental factors to the productivity or performance is very limited and characterized by a short time perspective or perception with emphasis on survey methods, statistical analysis, satisfaction and the preferences measurement. This study is done to prove empirically the previous perception studies based on the role of environmental factors to productivity. It is expected that this study would be beneficial to the automotive industries in Malaysia.The research findings are restricted to the Malaysian workplace environment, where the awareness among workers on productivity is still low. The results might vary for tests carried out for different sample sizes, types of industries and countries.

\section{REFERENCES}

1. American Society of Heating, 2005. ASHRAE Handbook-Fundamentals. Refrigerating and AirConditioning Engineers, Inc., Atlanta. ISBN: 1931862710.

2. Chubaj, C.A., 2002. School indoor air quality. J. Instruct. $\quad$ Psychol., 29: 317-321. https://www4.infotrieve.com/neworders/Order_Car t.asp

3. Si, C.T. and L.I. Tong, 1997. Multi response robust design by principal component analysis. Total Qual. Manage., 8: 409-416.

4. Zhang, C. and H.P. Wang, 1998. Robust design of assembly and machining tolerance allocations. IEE Trans., 30 : 17-29. http://cat.inist.fr/?aModele=afficheN\&cpsidt=2179 783

5. Dua, J.K., 1994. Job stressors and their effects on physical health, emotional health and job satisfaction in a University. J. Educ. Administ., 32: 59-78. DOI: 10.1108/09578239410051853

6. Ettner, S.L. and J.G. Grzywacz, 2001. Workers' perceptions of how jobs affect health: A social ecological perspective. J. Occupat. Health Psychol., 6: 101-131. http://www.ncbi.nlm.nih.gov/pubmed/11326723

7. Fanger, P.O., 1970. Thermal Comfort. Danish Technical Press, Copenhagen. ISBN: 0-07-0199159, pp: 21-23.

8. Fisk, W.J., 2000. Health and productivity gains from better indoor environments and their relationship with building energy efficiency. Annu. Rev. Energy Environ., 25: 537-566. DOI: 10.1146/annurev.energy.25.1.537 
9. Fisk, W.J. and A.H. Rosenfeld, 1997. Estimates of improved productivity and health from better indoor environments. Indoor Air, 7: 158-172. http://eetdnews.lbl.gov/cbs_nl/nl15/productivity.html

10. Gagge, A.P. and R.G. Nevins, 1976. Effect of energy conservation guideline, on comfort, acceptability and health. Final report of contract. http://www.osti.gov/energycitations/product.biblio. jsp?osti_id=5009419

11. Atmaca, I., Omer Kaynakli and Abdulvahap Yigit, 2007. Effects of radiant temperature on thermal comfort. Build. Environ., 42: 3210-3220. DOI: 10.1016/j.buildenv.2006.08.009

12. ISO 7730, 1994. Moderate thermal environments: Determination of the PMV and PPD indices and specification of the conditions for thermal comfort. http://www.cjwalsh.ie/tag/iso-7730-moderate-thermalenvironments-determination-of-the-pmv-and-ppdindices-and-specification-of-the-conditions-forthermal-comfort/

13. Budaiwi, I.M., 2007. An approach to investigate and remedy thermal comfort problems in buildings. Build. Environ., 42: 2124-2131. DOI: 10.1016/j.buildenv.2006.03.010

14. Kopac, J., M. Bahor and M. Sokovic, 2002. Optimal machinig parameters for achieving the desired surface roughness in fine turning of cold pre-formed steel workpieces. Int. J. Mach. Tool Manufacture., 42: 707-716. http://cat.inist.fr/?aModele $=$ afficheN\&cpsidt $=13609207$

15. Shek, K.W. and W.T. Chan, 2008. Combined comfort model of thermal comfort and air quality on buses in Hong Kong. Sci. Total Environ., 389: 277-282. http://www.ncbi.nlm.nih.gov/pubmed/17949792

16. Moss, K.J., 1998. Heat and Mass Transfer in Building Services Design. E and FN Spon, London and New York, ISBN: 0419226508, pp: 248.

17. Tsui, K.L., 1999. Modeling and analysis of dynamic robust design experiments. IEE Trans., 31: 113-1122. DOI: 10.1023/A:1007687928174

18. Parsons, K.C., 2000. Environmental ergonomics: A review of principles, methods and models. Applied Ergonomic 31: 581-594. http://cat.inist.fr/?aModele $=$ afficheN\&cpsidt $=8366$ 86

19. Leaman, A., 1995. Dissatisfaction and office productivity. Facilities, 13: 13-19. DOI: 10.1108/02632779510078102

20. Maher Hamdi, Gerard Lachiver and Francois Michand, 1999. A new predictive thermal sensation index of human response. Energy Build., 29: 167-178. DOI: 10.1016/S0378-7788(98)00054-1
21. Holmes, M.J. and J.N. Hacker, 2007. Climate change, thermal comfort and energy: Meeting the design challenges of the 21st century. Energy Build., 39: 802-814. DOI: 10.1016/j.enbuild.2007.02.009

22. Phadke, M.S., 1989. Quality Engineering Using Robust Design. Prentice Hall, New Jersey, ISBN: 13: 9780137451678, pp: 250.

23. Marshall, L., W. Erica, A. Alan and M.D. Sanborn, 2002. Identifying and managing adverse environmental health effects: 1. Taking an exposure history. Can. Medical Assoc. J., 166: 1049-1055.

http://biblioteca.universia.net/ficha.do? $\mathrm{id}=325333$

24. Olesen, B.W., 1995. International standards and the ergonomics of the thermal environment. J. Applied Ergonom., 26: 293-302. DOI: 10.1016/00036870(95)00033-9

25. Benardos, P.G. and G.C. Vosniakos, 2002. Prediction of Surface Roughness in CNC Face Milling Using Neural Networks and Taguchi's Design of Experiments. Robotics and Computer Integrated Manufacturing. 18: 343-354. DOI: 10.1016/S0736-5845(02)00005-4

26. Roberto Z. Freire, Gustavo H. C. Oliveira and Nathan Mendes, 2008. Predictive controllers for thermal comfort optimization and energy savings. Energy Build., 40: 1353-1365. DOI: 10.1016/j.enbuild.2007.12.007

27. Unal, R. and E.B. Dean, 1991. Taguchi approach to design optimization for quality and cost: An overview. Proceeding of the 13th Annual International Conference on Society of Parametric Analyst, May 21-24, pp: -10 . http://ntrs.nasa.gov/archive/nasa/casi.ntrs.nasa.gov/ 20040121019_2004117340.pdf

28. Shiaw-Fen Ferng, L.W.L., 2002. Indoor air quality assessment of day-care facilities with carbon dioxide, temperature and Humidity as Indicator. J. Environ. Health, 65: 14-18. http://www.ncbi.nlm.nih.gov/pubmed/12415886

29. Shikdar, A.A. and N.M. Sawaqed, 2003. Worker productivity and occupational health and safety issues in selected industries. Comput. Ind. Eng., 45: 563-572. http://portal.acm.org/citation.cfm?id=989503

30. Ho, S.H., L. Rosario and M.M. Rahman, 2008. Thermal comfort enhancement by using a ceiling fan. Applied Thermal Eng., 29: 1648-1656. DOI: 10.1016/j.applthermaleng.2008.07.015

31. Park, S.H., 1996. Robust Design and Analysis for Quality Engineering. Chapman and Hall, ISBN: 0412556200, pp: 344. 
32. Tarcan, E., E.S. Varol and M. Ates, 2004. A qualitative study of facilities and their environmental performance management of environmental quality. Int. J., 15: 154-173. DOI: 10.1108/14777830410523099

33. Health and Safety Executive Staff, Great Britain, Great Britain Health and Safety Executive, Health and Safety Executive, 1999. Thermal Comfort in the Workplace: Guidance for Employers Health and Safety Executive (HSE). 1st Edn., Health and Safety Executive (HSE), Norwich ISBN: 0717624684, pp: 20.

34. Lin, T.R., 2002. Experimental design and performance analysis of TiN-coated carbide tool in face milling stainless steel. J. Mater. Process. Technol., $\quad 5654$ : 1-7. http://cat.inist.fr/?aModele $=$ afficheN\&cpsidt $=1392$ 3452
35. Wilson, S., 2001. Graduating to Better AQ. Consult. Specif. Eng., 29: 24-28. http://www.eric.ed.gov/ERICWebPortal/custom/po rtlets/recordDetails/detailmini.jsp?_n

36. Yang, W.H. and Y.S. Tarng, 1998. Design optimization of cutting parameters for turning operations based on the Taguchi method. J. Mater. Process. Technol., 84: 122-129. DOI: 10.1016/S0924-0136(98)00079-X

37. Guan, Y., M. Hosni, B.W. Jones and T.P. Gielda, 2003. Literature review of the advances in thermal comfort modeling. ASHRAE Trans., 109: 908-916.

38. Zhang, Y. and R. Zhao, 2008. Overall thermal sensation, acceptability and comfort. Build. Environ., 43: 44-50. $\quad$ DOI: 10.1016/j.buidenv.2006.11.036 